\title{
Contribution of smoking to socioeconomic inequalities in mortality: a study of 14 European countries, 1990-2004
}

\author{
G Gregoraci, ${ }^{1,2} \mathrm{~F}$ J van Lenthe, ${ }^{1}$ B Artnik, ${ }^{3} \mathrm{M}$ Bopp ${ }_{1}^{4} \mathrm{P}$ Deboosere, ${ }^{5} \mathrm{~K}$ Kovács, ${ }^{6}$ \\ C W N Looman, ${ }^{1}$ P Martikainen, ${ }^{7}$ G Menvielle, ${ }^{8}$ F Peters, ${ }^{1}$ B Wojtyniak, ${ }^{9}$ \\ $\mathrm{R}$ de Gelder, ${ }^{1}$ J P Mackenbach, ${ }^{1}$ for the DEMETRIQ consortium
}

- Additional material is published online only. To view please visit the journal online (http://dx.doi.org/10.1136/ tobaccocontrol-2015-052766)

For numbered affiliations see end of article.

\section{Correspondence to}

Professor Johan P Mackenbach, Department of Public Health,

Erasmus MC, PO Box 2040,

Rotterdam 3000 CA,

The Netherlands:

j.mackenbach@erasmusmc.nl

Received 14 October 2015 Revised 4 March 2016 Accepted 31 March 2016 Published Online First 27 April 2016
CrossMark

To cite: Gregoraci $\mathrm{G}$ van Lenthe FJ, Artnik B, et al. Tob Control 2017:26:260-268.

\section{ABSTRACT}

Background Smoking contributes to socioeconomic inequalities in mortality, but the extent to which this contribution has changed over time and driven widening or narrowing inequalities in total mortality remains unknown. We studied socioeconomic inequalities in smoking-attributable mortality and their contribution to inequalities in total mortality in 1990-1994 and 20002004 in 14 European countries.

Methods We collected, harmonised and standardised population-wide data on all-cause and lung-cancer mortality by age, gender, educational and occupational level in 14 European populations in 1990-1994 and 2000-2004. Smoking-attributable mortality was indirectly estimated using the Preston-Glei-Wilmoth method.

Results In 2000-2004, smoking-attributable mortality was higher in lower socioeconomic groups in all countries among men, and in all countries except Spain, Italy and Slovenia, among women, and the contribution of smoking to socioeconomic inequalities in mortality varied between $19 \%$ and $55 \%$ among men, and between $-1 \%$ and 56\% among women. Since 1990-1994, absolute inequalities in smoking-attributable mortality and the contribution of smoking to inequalities in total mortality have decreased in most countries among men, but increased among women.

Conclusions In many European countries, smoking has become less important as a determinant of socioeconomic inequalities in mortality among men, but not among women. Inequalities in smoking remain one of the most important entry points for reducing inequalities in mortality.

\section{INTRODUCTION}

Reducing socioeconomic inequalities in mortality is an important challenge for public health and is one of the main priorities of the European Region of the WHO. ${ }^{1}$ Many different entry points for tackling health inequalities have been suggested, and among these smoking is an obvious candidate. In Europe, smoking is not only the largest avoidable health risk in the general population, ${ }^{2}$ but it also constitutes the single most important contributor to socioeconomic inequalities in mortality, at least among men. ${ }^{3-9}$ Unfortunately, although tobacco control efforts may have gradually contributed to reducing the prevalence of smoking among men in many countries, socioeconomic inequalities in smoking have increased in many European countries, due to faster declines of smoking among those with higher levels of education, occupation and income. ${ }^{1011}$

It is not well known to what extent these smoking trends have contributed to narrowing or widening inequalities in mortality. Over the past decades, socioeconomic inequalities in mortality have been widening in many European countries, at least on a relative scale. ${ }^{12} 13$ Modelling studies have suggested that declines in smoking contributed to a narrowing of absolute inequalities (AIs) in cardiovascular mortality in England, ${ }^{14}$ but studies in other countries and/or on total mortality are scarce.

Recently, Preston et $a l^{2}$ developed a method that allows an indirect estimation of smoking-attributable mortality and relies on using lung cancer death rates as an indicator of population exposure to smoking, building on the earlier work of Peto et al. ${ }^{15}$ This new method partially overcomes the generalisability limitations of the Peto-Lopez method, which uses lung cancer death rates for smokers and non-smokers, and relative risks of cause-specific mortality for smokers versus non-smokers from the US Cancer Prevention Study II (CPS-II). The CPS-II, however, is based on a sample of volunteers who are more likely to be white, middle class and college educated, and the Peto-Lopez method depends heavily on the assumption that the CPS-II estimates of lung cancer death rates for smokers and non-smokers, and relative risks, apply to other countries and across time. ${ }^{15}$ Preston et al developed an alternative approach for the indirect estimation of smoking-attributable mortality. Although this new method also uses lung cancer mortality as an indicator of smoking damage, it exploits the macrolevel statistical association between lung cancer mortality and mortality from all other causes of death, across countries and over time. ${ }^{2}$

Applying the new method, Martikainen et al ${ }^{16}$ showed an increase over time of the contribution of smoking to educational inequalities in mortality among Finnish women, and a decrease of this contribution among men. We have now applied this method to 1990-1994 and 2000-2004 data from 14 European countries, to examine the contribution of smoking to inequalities in mortality and the extent to which this contribution has changed over time and driven widening or narrowing inequalities in total mortality.

\section{DATA AND METHODS \\ Data sources}

We collected data on total and cause-specific mortality by age (35-79 years, except for Norway (40- 
79 years), Lithuania (35-69 years) and Poland (35-64 years)), gender, education and occupation, from population censuses and vital registries of 14 European countries (table 1) for the 1990-1994 and 2000-2004 periods. A more detailed description of data sources is provided in online supplementary file 1. Data relate to complete national populations, except for Italy, where we obtained data from Turin only and for Spain, with data from Barcelona only. Owing to the high percentage of older persons for which the occupational status was unknown, analyses by occupation were limited to ages 35-64 years.

Socioeconomic status was ascertained on the basis of education and occupation. Education was measured as the highest level of education attained by a person and coded according to the International Standard Classification of Education (ISCED-97) into three groups: up to lower secondary education (ISCED 0, 1 and 2; 'low'), completed secondary education (ISCED 3 and 4; 'mid') and tertiary education (ISCED 5 and 6; 'high'). In England and Wales, only two groups were available in the 1990-1994 period, those being ISCED 0-3 (classified as 'low' in the tables and graphs of this paper) and ISCED 4-6 ('high').

Data on mortality by occupational class among men were available for five countries. Persons' own occupations were classified according to the Erikson-Goldthorpe scheme as 'manual' or 'non-manual'; farmers and self-employed were excluded from the analysis. Since results are generally similar to those obtained for education, they will be presented in an online supplementary file.

\section{Methods}

We applied a method developed by Preston et al, ${ }^{17}$ which results in an indirect estimate of the smoking-attributable fraction (SAF) of total deaths in a population. In this so-called Preston-Glei-Wilmoth (PGW) method, age-specific and sexspecific lung cancer death rates are used as indicators of the damage from smoking. In brief, based on a regression analysis of data from 21 high-income countries for the period 1950 to 2007, Preston et al used the observed lung cancer deaths to predict mortality from other causes of death, and to estimate the impact of smoking on these other causes of death.

The method consists of four steps. The first step, which was conducted by Preston $e t$ al and does not need to be repeated in every application, uses a negative binomial regression to model annual mortality from causes other than lung cancer as a function of lung cancer mortality, taking into account age, calendar year, country of observation and several interactions, thus estimating the parameters to be used in step three. In the second step, the observed lung cancer death rates in the population of interest are compared to the CPS-II lung cancer death rates among non-smokers, thereby providing the population-attributable fraction of lung cancer due to smoking. In the third step, the proportion of deaths from causes other than lung cancer attributable to smoking is estimated by multiplying the excess mortality rate of lung cancer (as compared to the CPS-II lung cancer death rates among non-smokers) by a time-specific, age-specific and sex-specific parameter (estimated in step one). The fourth and final step combines the population-attributable fractions of lung cancer and of other causes mortality in a weighted average to produce the overall smoking-attributable fraction of deaths.

In the study reported here, we have taken the parameter estimates from the PGW-model (ie, from step 2 mentioned above), as published in Preston et al's $\mathrm{s}^{2}$ table 1 , and the lung cancer death rates in non-smokers, as observed in the CPS-II, ${ }^{18}$ together with the observed lung cancer death rates by country, period, sex, age and socioeconomic group, to estimate the fraction of all deaths attributable to smoking in each group.

Preston et al have demonstrated that their method produces results very similar to those obtained with the older and widely used method developed by Peto et al. ${ }^{15}$ The original PGW method was developed for persons aged 50 years and older. We included persons aged 35-79 years, and for those below the age of 50 years we used the extended version of the model recently described by Martikainen et al. ${ }^{19}$ The method is described in more detail in online supplementary file 2 .

We multiplied country-specific, period-specific, sex-specific, agespecific and socioeconomic group-specific smoking-attributable fractions (SAF) by their corresponding total mortality rates (TMR) to arrive at smoking-attributable mortality rates per 100000 person-years, and then computed age-standardised smoking-attributable mortality rates (SAMRs) for each country, period, sex and socioeconomic group, using the European Standard Population. ${ }^{20}$ TMR were likewise age-standardised. We then used the SAMRs and TMRs of the lowest and highest socioeconomic group to calculate both, rate differences (as a measure of $\mathrm{AI}$ ) and rate ratios (as a measure of relative inequalities (RI)). The proportion of the rate difference for SAMR out of the rate difference for TMR was taken as a measure of the contribution of inequalities in smoking-related mortality to inequalities in total mortality. CIs around estimates were calculated using parametric bootstrapping, ${ }^{19}$ assuming Poisson-distributed death counts and setting the number of repetitions to 1000 . The significance of changes over time in inequalities was calculated using pooled $t$ tests, based on the rate differences and RR, and their CIs, assuming normal distributions of the errors. Analyses were performed using Stata V.13.1 SE.

\section{RESULTS}

Among men, the SAF were always larger for those with a low level of education than for those with a high level of education (figure 1). Among women, the variation between socioeconomic groups was less pronounced. Over time, the SAFs generally fell among low educated men and rose among low educated women. Similar results were observed by occupational class (see online supplementary figure 1 ).

Table 2 shows age-standardised SAMRs by education. Among men, and without exception, SAMRs were highest among the low educated and lowest among the high educated. Over time, SAMRs decreased in almost all countries among men at each educational level, except in Hungary. Among women, SAMRs were generally much lower than among men, and only in some countries was an educational gradient clearly visible, especially in the North and West and in Poland. SAMRs tended to generally increase over time among women of all educational levels. Those for whom education was not known suffered the highest mortality rates (see online supplementary table S1). Essentially, similar results were observed for mortality by occupation among men: manual workers experienced higher SAMRs than nonmanual workers, and SAMRs declined over time in both groups in almost all countries with available data (see online supplementary table S2).

AIs in SAMRs were much larger among men than among women in all countries (figure 2A). Among women, particularly in the earlier period, some countries exhibited no or 'reverse' inequalities (favouring the lower educated) in SAMRs. Over time, AIs in SAMRs generally declined among men, while in Hungary, a large increase in AIs occurred. By contrast, among women, AIs in SAMRs increased in most countries, with the sole exception of England and Wales. RIs in SAMRs (figure 2B) 


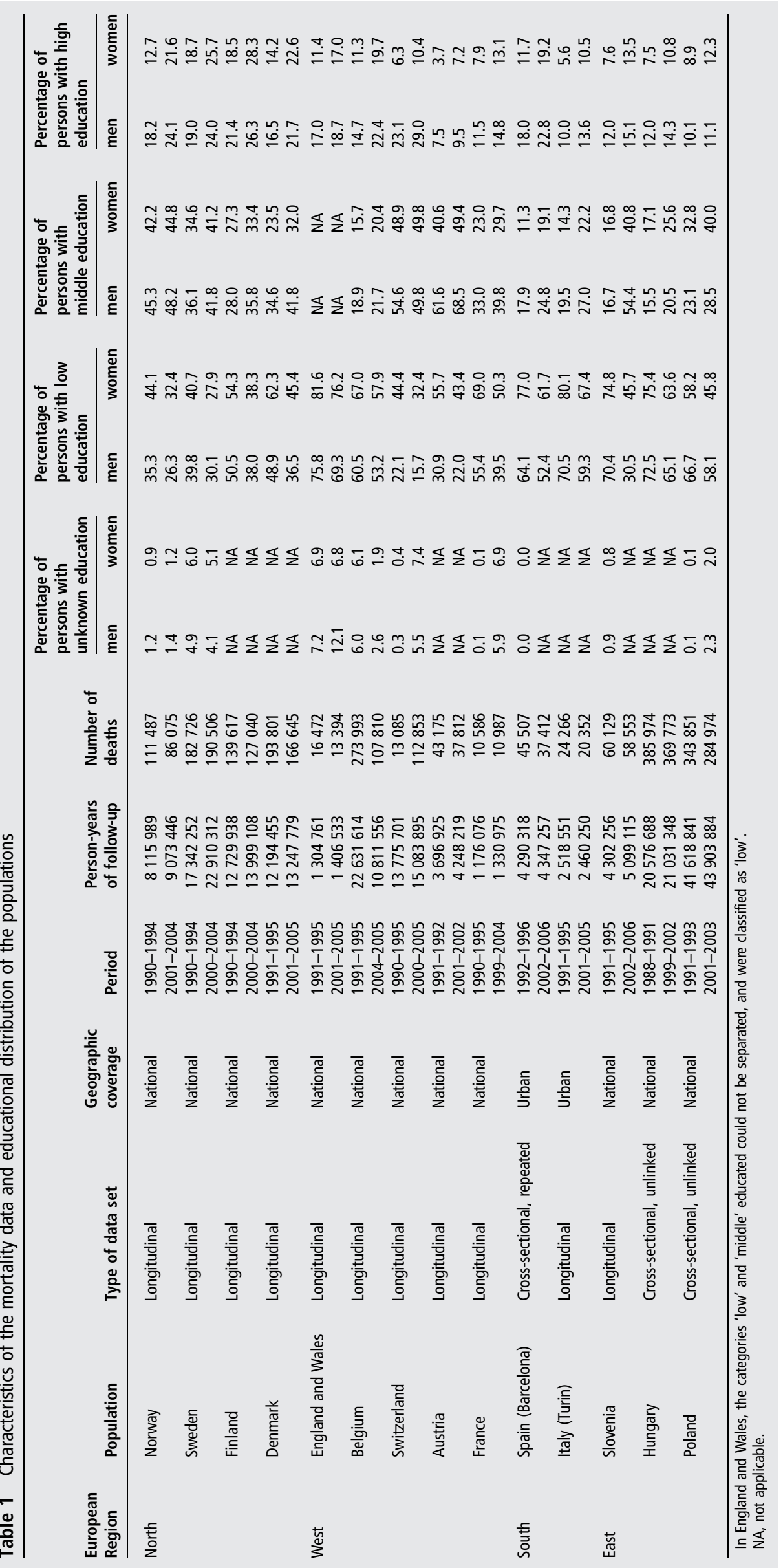


Figure 1 Age-standardised smoking-attributable fractions with $95 \%$ Cls in 14 European populations, 1990-1994 and 2000-2004, by sex and by $(\mathrm{A})$ low, (B) middle and (C) high level of education.

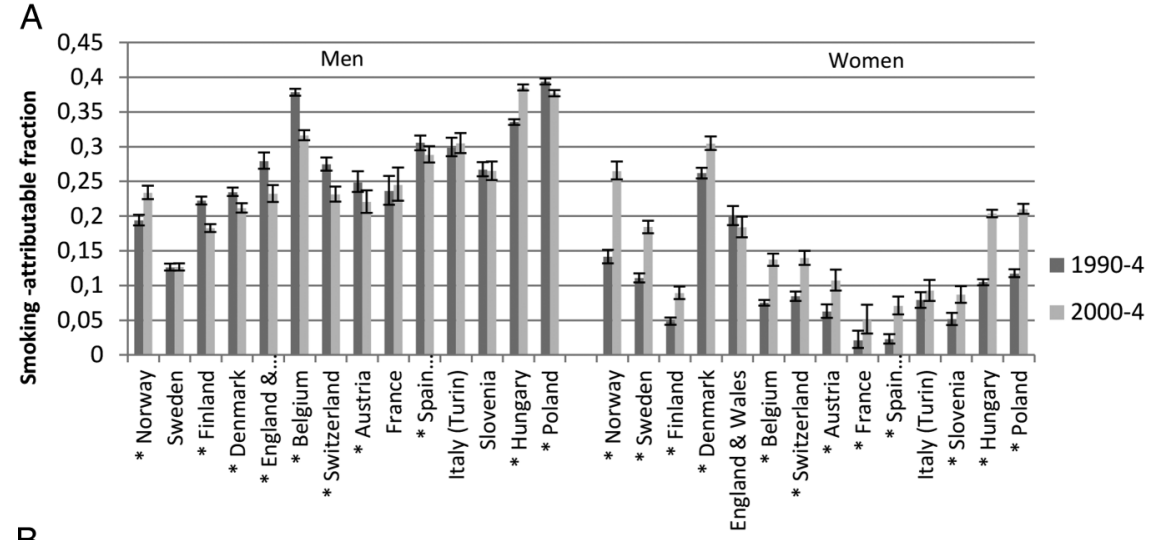

B
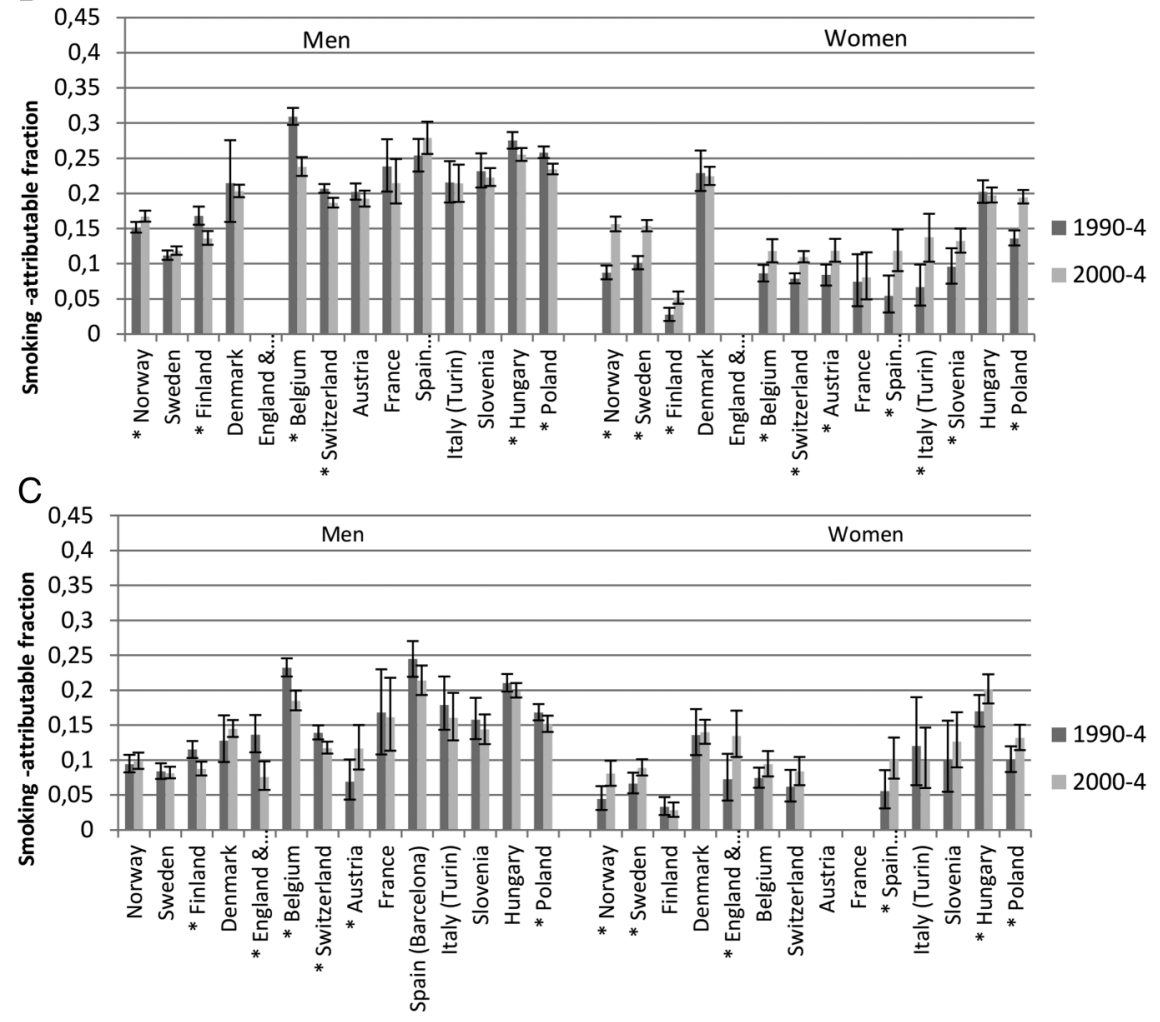

tended to increase in most countries, especially among men. The contribution of smoking-attributable mortality to AIs in total mortality decreased in many countries among men, but increased in several countries among women (figure 2C). Similar results were observed by occupational class (see online supplementary figure 2).

Figure 3 shows how changes over time in AIs in SAMRs relate to changes in inequalities in TMRs. Among men, AIs in TMRs have fallen in many countries, and more so when AIs in smoking-attributable mortality further decreased $\left(\mathrm{R}^{2}=0.80\right)$. Among women, the trends are less favourable, but here again there is a correlation $\left(\mathrm{R}^{2}=0.20\right)$.

\section{DISCUSSION}

\section{Strengths and limitations}

Our study is the first to apply the new PGW method to inequalities in mortality in such a wide range of countries. This unique coverage, however, comes with a few caveats. Our data came from countries with different practices of data collection, which may affect comparability, for example, as a result of using both longitudinal census-linked and cross-sectional unlinked data. $^{21} 22$ Differences between countries in geographic and demographic coverage may also play a role. Swiss data, for example, did not include foreign nationals and, due to a healthy migrant effect, inequalities in that country may have been slightly overestimated. ${ }^{23}$ Italy and Spain did not provide national but provided only urban data, therefore small inequalities in those countries have also been observed when using national data. ${ }^{24} 25$

No single socioeconomic indicator fully captures the complexity of a person's socioeconomic position. ${ }^{26}$ However, results by occupational class generally showed a picture similar to that by educational level, suggesting that we are generally observing a pattern of mortality by socioeconomic position. Persons for whom education was unknown had the highest smoking-attributable mortality rates (see online supplementary table S1), and if those persons in reality had mostly had a lower education, our comparisons between low and high educated will have underestimated the real magnitude of inequalities in smoking-attributable mortality. As the proportion with 


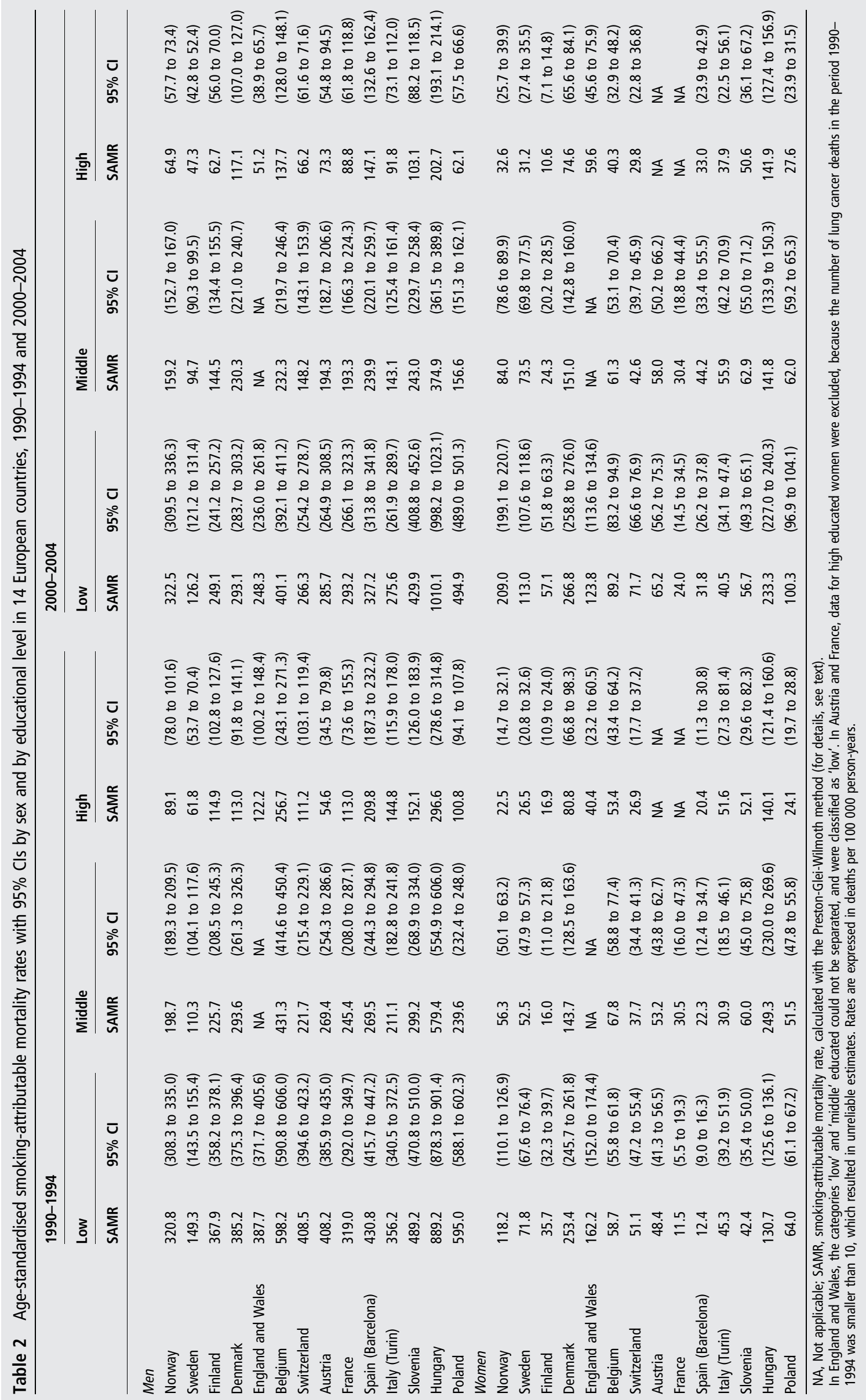


Figure 2 Absolute $(A)$ and relative (B) inequalities in smoking-attributable mortality by sex and by educational level, and (C) contribution of smoking to absolute inequalities in total mortality in 14 European countries in 1990-1994 and 2000-2004, by sex. SAMRs, smoking-attributable mortality rates; TMR, total mortality rates.

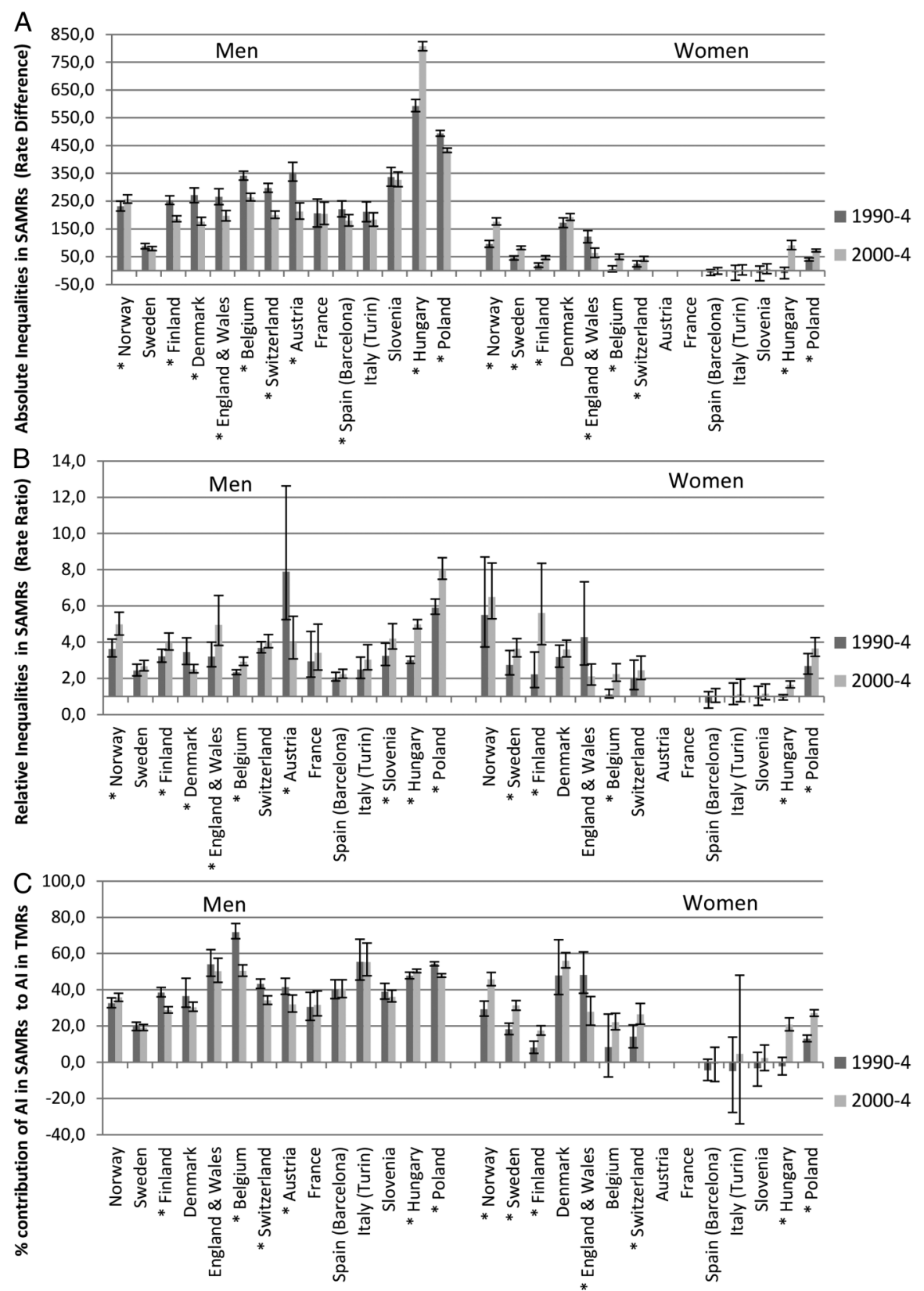

education unknown also changed over time (table 1), this exclusion may also have biased our estimates of changes in inequalities. In England and Wales, no distinction could be made between the 'low' and 'mid' educated. However, when data for all countries were categorised as 'low'/'mid' versus 'high' educated, similar patterns and changes over time were observed (results not shown).

The PGW method relies on several assumptions. The first assumption is that smoking is the main source of variability in lung cancer death rates-an assumption that would be violated if, for example, certification and coding of lung cancer as a cause of death differ between countries, but as lung cancer is a relatively straightforward cause of death, this is likely to only be a minor problem. ${ }^{27} 28$ The second assumption is that lung cancer among never smokers is stable over time and across countries-an assumption that would be violated if, for example, decreasing levels of air pollution would lead to a decline of lung cancer incidence ${ }^{29}$ or risks of lung cancer among non-smokers would be higher in some countries. ${ }^{30}$ Also, non-smoking behaviour in the CPS-II cohort was assessed only at enrolment, therefore CPS-II rates are affected by misclassification of non-smokers, ${ }^{31}$ and as they also do not account for passive smoking they probably overestimate the real lung cancer rates in absence of smoking. This suggests that the PGW method may underestimate the true impact of smoking. The third assumption is that lung cancer death rates in a calendar year are a valid proxy for the total damage of smoking as it occurs in that calendar year, including both the short-term and long-term effects. ${ }^{18} 32$ This implies that the PGW method may overestimate smoking-attributable mortality when smoking prevalence has in previous years substantially declined, as it has in many countries among men, because risks of cardiovascular disease decline faster than those of lung cancer. ${ }^{33}$

A new assumption in our work is that the lung cancer mortality rate among never smokers and the effect of smoking on mortality from other causes of death are similar across socioeconomic groups. Low socioeconomic status non-smokers may have a higher risk of developing lung cancer than high socioeconomic 


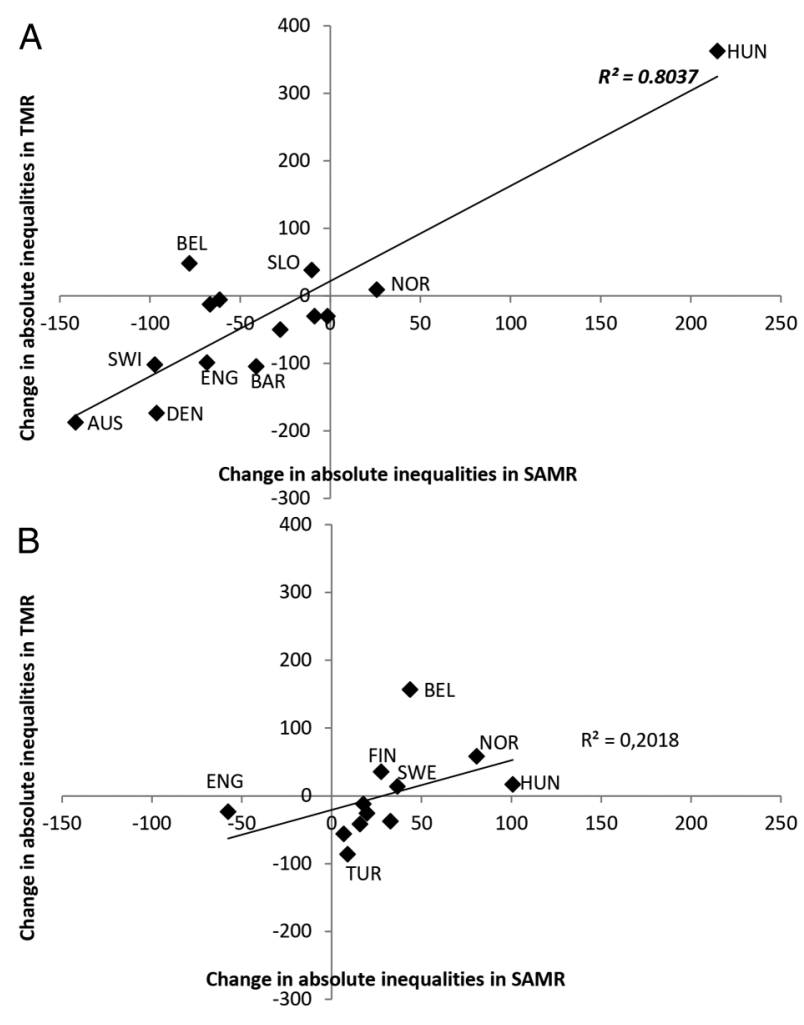

Figure 3 Changes in absolute educational inequalities in smoking-attributable and total mortality in 14 European countries between 1990-1994 and 2000-2004, for (A) men and (B) women. SAMRs, smoking-attributable mortality rates; TMR, total mortality rates.

status non-smokers because of higher environmental or occupational exposure to carcinogens and pollutants. ${ }^{29}{ }^{34-37}$ If this is indeed the case, it will lead to overestimation of the impact of smoking on mortality in lower socioeconomic groups, and thus on socioeconomic inequalities in mortality. However, another mechanism may lead to underestimation of the impact of smoking on socioeconomic inequalities in mortality: the PGW method does not take into account that the effect of smoking on mortality from causes other than lung cancer may be larger in lower socioeconomic groups because survival of chronic obstructive pulmonary disease (COPD), myocardial infarction and other smoking-related diseases may be affected by lower access or quality of medical care. ${ }^{38} 39$

More generally, the PGW parameters as calculated in the first step are applicable under the assumption that the distribution of deaths over specific non-lung cancer causes, some of which are more sensitive to smoking than others, is similar across countries, over time and, in our case, across socioeconomic groups. This potential problem was already highlighted in Preston $e t a l^{2}$ in relation to Japan, a country with extremely low mortality from ischaemic heart disease, for which the PGW method may therefore somewhat overestimate the contribution of smoking. In our data set, variations in proportional mortality from cardiovascular disease are well within the range of the majority of Preston et al's observations, and there are only minor variations in proportional mortality between socioeconomic groups. However, France stands out as a country with very low proportional mortality owing to cardiovascular disease, particularly among women, and even more strongly so among high educated women (results not shown). This suggests that we may have overestimated the contribution of smoking to mortality in France.
Despite these limitations, the PGW method provided robust results. Sensitivity analyses assuming 50\% higher lung cancer mortality rates in low educated non-smokers confirmed the findings reported above, and when compared to our main results they showed a reduction in AIs in SAMRs of about 15 deaths/ 100000 person-years in all countries and both genders, or a reduction of only $1-3 \%$ in terms of smoking-attributable fractions (results not shown). We also compared the 'indirect' estimates based on the PGW method with 'directly' estimated SMARs. The latter were calculated as the sum of three causes of death that are largely caused by smoking (lung cancer, upper $113, \mathrm{COPD} /$ asthma). The correlation between the two was high $\left(\mathrm{R}^{2}=0.94\right)$. The direct estimates, however, were always much lower than the indirect estimates, reflecting the fact that the PGW estimates include deaths from, for example, smokingrelated cardiovascular disease (see online supplementary figure 3).

\section{Interpretation}

In the early 2000s, the contribution of smoking to socioeconomic inequalities in mortality in these European populations varied between $19 \%$ and $55 \%$ among men, and between -1 and $56 \%$ among women. Our current findings are broadly in line with our two previous studies based on different methodologies. In the first study, we found that the contribution of three smoking-related causes (lung cancer, aerodigestive cancers, COPD) to inequalities in all-cause mortality varied between $13 \%$ and $32 \%$ among men, and $-5 \%$ and $30 \%$ among women. ${ }^{4}$ In the second study, we used current smoking prevalence rates by socioeconomic group and RR of mortality among smokers and non-smokers, and estimated that the contribution of smoking to inequalities in total mortality varied between $4 \%$ and $26 \%$ among men, and $1 \%$ and $20 \%$ among women. ${ }^{7}$ Patterns of variation between countries are generally similar between the three methods. That our new estimates are generally higher than those obtained with the direct method based on three smoking-related causes of death is unsurprising (see above). That our estimates are also higher than those obtained with current smoking rates suggests that either our new estimates are too high (because the PGW method overestimates the impact of smoking when smoking prevalence decreases over time) or that estimates based on current smoking rates are too low (because they do not take into account all the damage of smoking in current and previous years). ${ }^{33}$ In-depth analyses of more detailed country-specific data on trends in mortality and smoking prevalence by socioeconomic position will be necessary to elucidate the causes of these discrepancies.

Among men, the reduction in the contribution of smoking to mortality inequalities between 1990-1994 and 2000-2004 is due to an overall reduction in smoking-attributable mortality over time. Over the past half century, men across Europe started to quit smoking and as a result are dying less and less from direct and indirect smoking-related causes. Since this happened earlier, and at a faster rate among men in higher socioeconomic groups, ${ }^{4} 40$ a well-known gap in smoking prevalence has opened up, particularly in the North and West of Europe. ${ }^{41}{ }^{42}$ How this plays out in inequalities in mortality has, however, not been systematically studied. Our study shows that, although RIs in smoking-attributable mortality among men have increased over time, AIs have actually fallen in many countries.

To the extent that these reductions in smoking-attributable mortality were due to the antismoking campaigns conducted from the 1960s onwards, our findings seemingly contradict suggestions that tobacco control efforts tend to contribute to 
widening inequalities in mortality. ${ }^{11}$ Systematic reviews have shown that the effectiveness of policies and interventions to reduce inequalities in smoking is limited, and that only some policies have a larger impact on lower than among higher socioeconomic groups, such as a consistent increase in the price of tobacco products. ${ }^{43} 44$ Previous studies have, however, not always made a clear distinction between relative and absolute inequalities, and our results show that widening RIs can go together with narrowing absolute inequalities. We believe that AIs are more important than RIs-because the lives of people in lower socioeconomic groups are damaged more by a large absolute than by a large relative excess of health problems ${ }^{45}$-and therefore argue that our findings should encourage countries to continue and further tighten their tobacco control policies.

The good news mainly concerns men in the North, West and South of Europe. Among women, we observe increasing SAMRs in lower socioeconomic groups, as well as increasing AIs in SAMRs. Hidden below these widening inequalities is the fact that rates of smoking-attributable mortality are still rising among high educated women in many countries (table 2). While these differences between genders, countries and socioeconomic groups can be seen as following from differences in progression of the 'smoking epidemic', ${ }^{4}$ perhaps also reflecting different rates of women's emancipation ${ }^{46}$ they also represent a spectacular failure of tobacco control policies to prevent women from taking up smoking, and to prevent a repetition of what happened to inequalities in smoking among men. Our results suggest that, if the widening of inequalities in smoking-attributable mortality among women continues, this may become an important driver for widening inequalities in total mortality (figure 3 ).

Together with the fact that smoking accounts for up to half of inequalities in total mortality in some countries, our results imply that smoking remains one of the most important entry points for policies to tackle health inequalities.

\section{What this paper adds}

- It is known that socioeconomic inequalities in smoking have increased in many European countries.

- It is not well known to what extent smoking trends have contributed to narrowing or widening socioeconomic inequalities in total mortality.

- This study shows that, over time, smoking has become less important as a determinant of socioeconomic inequalities in mortality among men, but not among women.

- Our results imply that smoking remains one of the most important entry points for policies to tackle health inequalities.

\section{Author affiliations}

${ }^{1}$ Department of Public Health Rotterdam, Erasmus MC, University Medical Center Rotterdam, Rotterdam, The Netherlands

${ }^{2}$ Department of Medical and Biological Sciences, University of Udine, Institute of Hygiene and Clinical Epidemiology, Udine, Italy

${ }^{3}$ Department of Public Health, Faculty of Medicine, University of Ljubljana, Ljubljana, Slovenia

${ }^{4}$ Department of Epidemiology, Biostatistics and Prevention Institute, University of Zürich, Zürich, Switzerland

${ }^{5}$ Department of Sociology, Vrije Universiteit Brussel, Brussels, Belgium

${ }^{6}$ Demographic Research Institute of the Central Statistical Office, Budapest, Hungary

${ }^{7}$ Department of Sociology, University of Helsinki, Helsinki, Finland

${ }^{8}$ Institut Pierre Louis d'Epidémiologie et de Santé Publique (IPLESP UMRS 1136),

Sorbonne Universités, UPMC Univ Paris 06, INSERM, Paris, France
}

${ }^{9}$ Department Centre of Monitoring and Analyses of Population Health, National Institute of Public Health, National Institute of Hygiene, Warsaw, Poland

Acknowledgements The authors thank the members of the DEMETRIQ consortium for their valuable comments and suggestions on a previous version of the manuscript. The authors also thank Professor Samuel Preston for his comments on a previous version of this paper.

Collaborators Other members of the DEMETRIQ consortium who have contributed to this study, in addition to the named co-authors of this paper, are: Johannes Klotz (Statistics Austria, Vienna, Austria); Jørn Korsbø Petersen (Statistics Denmark, Copenhagen, Denmark), Office for National Statistics (Newport, Wales); Giuseppe Costa (Department of Clinical Medicine and Biology, University of Turin, Turin, Italy); Carme Borrell (Agència de Salut Pública de Barcelona, Barcelona, Spain); Bjorn Heine Strand (Division of Epidemiology, Norwegian Institute of Public Health, Oslo, Norway); Olle Lundberg (Center for Health Equity Studies, Stockholm, Sweden).

Contributors GG, FJvL and JPM made substantial contributions to the conception or design of the work. All the authors made substantial contributions to the acquisition, analysis and interpretation of data for the study. All the authors were involved in drafting the manuscript and revising it critically for important intellectual content. All the authors approved the final version to be published.

Funding Supported by a grant (FP7-CP-FP grant number 278511) from the European Commission Research and Innovation Directorate General, as part of the 'Developing methodologies to reduce inequalities in the determinants of health' (DEMETRIQ) project.

\section{Competing interests None declared.}

Provenance and peer review Not commissioned; externally peer reviewed.

\section{REFERENCES}

1 Marmot M, Allen J, Bell R, et al. WHO European review of social determinants of health and the health divide. Lancet 2012;380:1011-29.

2 Preston SH, Glei DA, Wilmoth JR. A new method for estimating smoking-attributable mortality in high-income countries. Int J Epidemiol 2010;39:430-8

3 Eikemo TA, Hoffmann R, Kulik MC, et al. How can inequalities in mortality be reduced? A quantitative analysis of 6 risk factors in 21 European populations. PLoS ONE 2014;9:e110952.

4 Kulik MC, Menvielle G, Eikemo TA, et al. Educational inequalities in three smoking-related causes of death in 18 European populations. Nicotine Tob Res 2014;16:507-18

5 Mackenbach JP, Stirbu I, Roskam AJ, et al. Socioeconomic inequalities in health in 22 European countries. N Engl J Med 2008;358:2468-81.

6 Jha P, Peto R, Zatonski W, et al. Social inequalities in male mortality, and in male mortality from smoking: indirect estimation from national death rates in England and Wales, Poland, and North America. Lancet 2006;368:367-70.

7 Kulik MC, Hoffmann R, Judge K, et al. Smoking and the potential for reduction of inequalities in mortality in Europe. Eur J Epidemiol 2013;28:959-71.

8 Mackenbach JP, Huisman M, Andersen 0 , et al. Inequalities in lung cancer mortality by the educational level in 10 European populations. Eur J Cancer 2004;40:126-35

9 Van der Heyden $\mathrm{JH}$, Schaap MM, Kunst AE, et al. Socioeconomic inequalities in lung cancer mortality in 16 European populations. Lung Cancer 2009;63:322-30.

10 Giskes K, Kunst AE, Benach J, et al. Trends in smoking behaviour between 1985 and 2000 in nine European countries by education. J Epidemiol Community Health 2005;59:395-401.

11 Schaap MM, Kunst $A E$, Leinsalu $M$, et al. Effect of nationwide tobacco control policies on smoking cessation in high and low educated groups in 18 European countries. Tob Control 2008;17:248-55.

12 Mackenbach JP, Bos V, Andersen O, et al. Widening socioeconomic inequalities in mortality in six Western European countries. Int J Epidemiol 2003:32:830-7.

13 Mackenbach JP, Kulhanova I, Menvielle G, et al. Trends in inequalities in premature mortality: a study of 3.2 million deaths in 13 European countries. J Epidemiol Community Health 2015;69:207-17; discussion 05-6.

14 Bajekal M, Scholes S, Love $\mathrm{H}$, et al. Analysing recent socioeconomic trends in coronary heart disease mortality in England, 2000-2007: a population modelling study. PLoS Med 2012;9:e1001237.

15 Peto R, Lopez AD, Boreham J, et al. Mortality from tobacco in developed countries: indirect estimation from national vital statistics. Lancet 1992;339:1268-78.

16 Martikainen $\mathrm{P}, \mathrm{Ho} J \mathrm{Y}$, Preston $\mathrm{S}$, et al. The changing contribution of smoking to educational differences in life expectancy: indirect estimates for Finnish men and women from 1971 to 2010. J Epidemiol Community Health 2013;67:219-24.

17 Preston SH, Glei DA, Wilmoth JR. Contribution of smoking to international differences in life expectancy. In: Crimmins EM, Preston SH, Cohen B, eds. International differences in mortality at older ages: dimensions and sources. Washington DC: National Academies Press (US), 2011:105-31 
18 Thun MJ, Day-Lally C, Myers DG, et al. Trends in tobacco smoking and mortality from cigarette use in cancer prevention studies I (1959 through 1965) and II (1982 through 1988). In: Burns DM, Garfinkel L, Samet JM, eds. Changes in cigarette-related disease risks and their implications for prevention and control, smoking and tobacco control. Bethesda, MD: Cancer Control and Population Sciences, National Cancer Institute, U.S. National Institutes of Health, 1997:305-82.

19 Martikainen P, Makela P, Peltonen R, et al. Income differences in life expectancy: the changing contribution of harmful consumption of alcohol and smoking. Epidemiology 2014;25:182-90.

20 Ahmad OB, Boschi-Pinto C, Lopez AD, et al. Age Standardization of Rates: a New WHO Standard. GBP Discussion Paper. World Health Organization, 2001.

21 Kunst $A E$, Groenhof F, Borgan JK, et al. Socio-economic inequalities in mortality. Methodological problems illustrated with three examples from Europe. Rev Epidemiol Sante Publique 1998;46:467-79.

22 Shkolnikov VM, Jasilionis D, Andreev EM, et al. Linked versus unlinked estimates of mortality and length of life by education and marital status: evidence from the first record linkage study in Lithuania. Soc Sci Med 2007;64:1392-406.

23 Tarnutzer S, Bopp M, Group SNCS. Healthy migrants but unhealthy offspring? A retrospective cohort study among Italians in Switzerland. BMC Public Health 2012;12:1104.

24 Marinacci C, Grippo F, Pappagallo M, et al. Social inequalities in total and cause-specific mortality of a sample of the Italian population, from 1999 to 2007. Eur J Public Health 2013;23:582-7.

25 Regidor $E$, Kunst AE, Rodriguez-Artalejo F, et al. Small socio-economic differences in mortality in Spanish older people. Eur J Public Health 2012;22:80-5.

26 Galobardes B, Shaw M, Lawlor DA, et al. Indicators of socioeconomic position (part 1). J Epidemiol Community Health 2006;60:7-12.

27 Lopez AD. The lung cancer epidemic in developed countries. In: Lopez AD, Caselli $\mathrm{G}$, Valkonen T, eds. Adult mortality in developed countries from description to explanation. Oxford, UK: Clarendon Press, 1995:179-200.

28 Mackenbach JP, Van Duyne WM, Kelson MC. Certification and coding of two underlying causes of death in The Netherlands and other countries of the European Community. J Epidemiol Community Health 1987;41:156-60.

29 Chen F, Cole P, Bina WF. Time trend and geographic patterns of lung adenocarcinoma in the United States, 1973-2002. Cancer Epidemiol Biomarkers Prev 2007;16:2724-9.

30 Brennan P, Crispo A, Zaridze D, et al. High cumulative risk of lung cancer death among smokers and nonsmokers in Central and Eastern Europe. Am J Epidemiol 2006;164:1233-41.

31 Garfinkel L. Selection, follow-up, and analysis in the American Cancer Society prospective studies. Natl Cancer Inst Monogr 1985;67:49-52.
32 Doll $\mathrm{R}$, Peto $\mathrm{R}$, Boreham J, et al. Mortality from cancer in relation to smoking: 50 years observations on British doctors. Br J Cancer 2005;92:426-9.

33 Oza S, Thun MJ, Henley SJ, et al. How many deaths are attributable to smoking in the United States? Comparison of methods for estimating smoking-attributable mortality when smoking prevalence changes. Prev Med 2011;52:428-33.

34 Hubaux R, Becker-Santos DD, Enfield KS, et al. Arsenic, asbestos and radon: emerging players in lung tumorigenesis. Environ Health 2012;11:89.

35 Lissowska J, Bardin-Mikolajczak A, Fletcher T, et al. Lung cancer and indoor pollution from heating and cooking with solid fuels: the IARC international multicentre case-control study in Eastern/Central Europe and the United Kingdom. Am J Epidemiol 2005;162:326-33.

36 Liu Q, Sasco AJ, Riboli E, et al. Indoor air pollution and lung cancer in Guangzhou, People's Republic of China. Am J Epidemiol 1993;137:145-54.

37 Menvielle $G$, Truong $T$, Jellouli $F$, et al. Education and lung cancer among never smokers. Epidemiology 2014;25:934-5.

38 Bongers IM, van der Meer JB, van den Bos J, et al. Socio-economic differences in general practitioner and outpatient specialist care in The Netherlands: a matter of health insurance? Soc Sci Med 1997;44:1161-8.

39 Koster A, Bosma H, Kempen $\mathrm{Gl}$, et al. Socioeconomic inequalities in mobility decline in chronic disease groups (asthma/COPD, heart disease, diabetes mellitus, low back pain): only a minor role for disease severity and comorbidity. J Epidemiol Community Health 2004;58:862-9.

40 Huisman M, Kunst AE, Mackenbach JP. Educational inequalities in smoking among men and women aged 16 years and older in 11 European countries. Tob Control 2005; 14:106-13

41 Cavelaars $A E$, Kunst $A E$, Geurts JJ, et al. Educational differences in smoking: international comparison. BMJ 2000;320:1102-7.

42 Huisman M, Kunst AE, Mackenbach JP. Inequalities in the prevalence of smoking in the European Union: comparing education and income. Prev Med 2005; 40:756-64

43 Main C, Thomas S, Ogilvie D, et al. Population tobacco control interventions and their effects on social inequalities in smoking: placing an equity lens on existing systematic reviews. BMC Public Health 2008;8:178.

44 Thomas S, Fayter D, Misso K, et al. Population tobacco control interventions and their effects on social inequalities in smoking: systematic review. Tob Control 2008; 17:230-7.

45 Mackenbach JP. Should we aim to reduce relative or absolute inequalities in mortality? Eur J Public Health 2015;25:185.

46 Schaap MM, Kunst AE, Leinsalu $M$, et al. Female ever-smoking, education, emancipation and economic development in 19 European countries. Soc Sci Med 2009;68:1271-8. 